\title{
A truly new view from the summit: from translational science to outcomes research in clinical arrhythmology
}

\author{
Sanjeev Saksena
}

Published online: 17 February 2010

(C) Springer Science+Business Media, LLC 2010

A new year brings invariably reflections of past achievements and some peering into the future. This year, the Journal begins its 13 th year with a new look. The new cover dwells, perhaps very briefly, on the long journey of clinical cardiac arrhythmology, but mostly symbolizes a truly new vision of the future of our field. We have come far from the diagnostic recording science of our pioneering early teachers. Only 20 years ago, we were actually searching for acceptable terminology to describe defibrillation therapy among ourselves and the term implantable cardioverter-defibrillator or ICD was first proposed [1]. Adoption of the term defibrillator into day to day speech occurred within a decade. Today, clinical electrophysiology has assimilated basic and translational science-, medical technology-, and evidence-based medicine with astonishing speed. Arrhythmia courses for the clinical practitioner used to be initiated often with electrocardiographic diagnosis, fundamentals of biostimulation, or clinical pharmacology of antiarrhythmics. Now, there is a very different flavor. We still continue to discuss these core subjects, but mainstream discussions include translational science, genomics, clinical syndromes with interwoven discussions of cellular and clinical electrophysiology, medical and surgical interventions, and invariably consolidate information in an evidence-based approach [2-5]. Sudden arrhythmic death syndromes now regularly appear in media discussion, with public awareness being driven by lay groups $[6,7]$. While individual interventions continually wax and wane in popularity, it is clearer now than ever before that cardiac arrhythmology has found new frontiers for exploration.

S. Saksena $(\square)$

UMDNJ - Robert Wood Johnson Medical School,

161 Washington Valley Road, Suite 201,

Warren, NJ 07059, USA

e-mail: cmenj@aol.com
This journal, as expressed by both cover and content, is committed to bring these to you.

Since the inception of the Journal, we have been focused on web-based access to content through institutional and individual access. Multimedia submissions were introduced 3 years ago and are continuing to grow. We have continued to streamline our processes to bring information to readers in a timely manner. Our web-based approach has been strengthened with the appointment of Dr. Turakhia as Associate Editor for Online Content. We are expanding the online commitment to include an Online Journal Library and Blog. Online access to the journal is allowing access for readership worldwide and is a membership feature for members of affiliated organizations such as the European Cardiac Arrhythmia Society. As noted in past commentaries, this journal was among the first to adopt online submission and review. Time to first decision from manuscript submission in 2009 was 26 days. Time from acceptance to online publication and indexing is now less than 3 months.

Our relationship with the European Cardiac Arrhythmia Society continues to promote one of the original fundamental aims of the Journal, namely, to widen dissemination of new information in this field. Scientific presentations at their annual meeting are abstracted in the Journal. Fostering such initiatives permits researchers and practitioners of cardiac arrhythmology, who may have either been geographically less represented in medical publications or have more limited access to them, to join in a global information exchange.

As we enter a new period where the greater visibility of this field now has a more impressive and an immediate impact on those whose interests we serve, it becomes increasingly incumbent on medical publications to provide critical and balanced content. The Journal is a member of the HEART group of medical editors and subscribes to policies approved by the group. This has, in the recent past, 
included the adoption of policies regarding conflicts of interest and publication ethics [8]. More extensive demands for transparency for all concerned in publication of research and limiting influences in reporting research are now being widely suggested [9]. These will clearly produce inevitable changes in the manner in which research submissions are developed, processed, and published.

To paraphrase Sir Edmund Hillary, there is a truly new view from the summit. While it may lack "the roar of a thousand tigers" characterizing the Himalayan summit, there remain many challenges ahead for the Journal. The editorial team has led this journal well and been instrumental in its success. New associate editors, Drs. Epstein and Lewalter, have joined the team in 2009. To the many reviewers, my colleagues the associate editors, and the staff at Springer, I would like to express my great appreciation for their invaluable efforts and recognize their important continuing contributions to the success of the Journal.

\section{Sanjeev Saksena \\ Editor in Chief}

\section{References}

1. Saksena, S. (1989). Antiarrhythmic devices: in search of a common parlance. PACE, 12, 1579-1582. Editorial.

2. Rosen, M. R., Brink, P. R., Cohen, I. S., Danilo, P., Jr., Robinson, R. B., Rosen, A. B., et al. (2008). Regenerative therapies in electrophysiology and pacing. Journal of Interventional Cardiac Electrophysiology, 22(2), 87-98.

3. Roden, D. M. (2004). Human genomics and its impact on arrhythmias. Trends in Cardiovascular Medicine, 14(3), 112-116.

4. Van Houzen, N. E., Alsheikh-Ali, A. A., Garlitski, A. C., Homoud, M. K., Weinstock, J., Link, M. S., et al. (2008). Short QT syndrome review. Journal of Interventional Cardiac Electrophysiology, 23(1), $1-5$.

5. Lall, S. C., \& Damiano, R. J., Jr. (2007). Surgical ablation devices for atrial fibrillation. Journal of Interventional Cardiac Electrophysiology, 20(3), 73-82.

6. C.A.R.E. Foundation. Retrieved from http://www.longqt.org.

7. Arrhythmia Alliance. Retrieved from http://www.heartrhythmcharity. org.uk.

8. HEART Group. (2008). A statement on ethics from the HEART Group. Journal of Interventional Cardiology, 21(3), 279-281.

9. International Committee of Medical Journal Editors Publication Ethics: Sponsorship, Authorship, and Accountability Uniform Requirements for Manuscripts Submitted to Biomedical Journals: Writing and Editing for Biomedical Publication. 